\title{
KNOWLEDGE BASED CONTROL OF ENERGY INSTALLATIONS UNDER UNCERTAIN CONDITIONS
}

\author{
V.N. Khokhlovskiy, V.V. Potekhin \& V.P.Shkodyrev
}
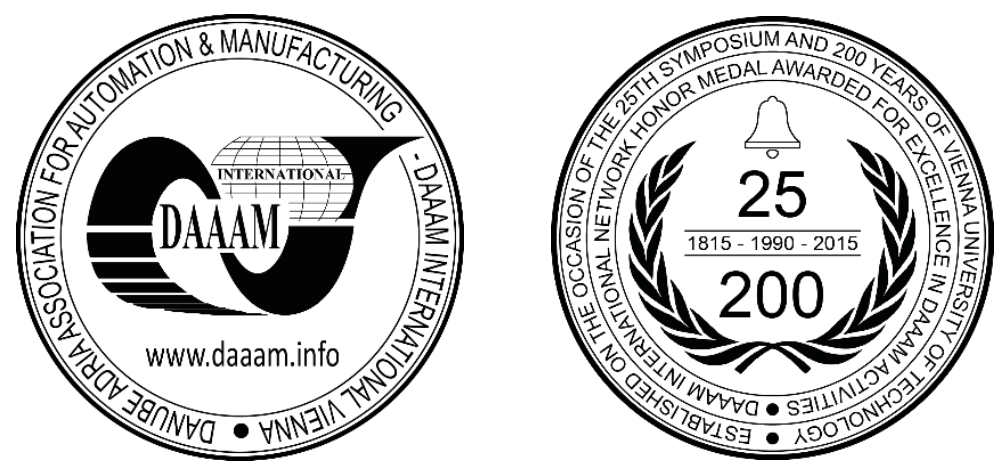

This Publication has to be referred as: Khokhlovskiy, V[ladimir]; Potekhin, V[yacheslav] \& Shkodyrev, V[iacheslav] (2018). Knowledge Based Control of Energy Installations Under Uncertain Conditions, Proceedings of the 29th DAAAM International Symposium, pp.0582-0586, B. Katalinic (Ed.), Published by DAAAM International, ISBN 978-3-90273420-4, ISSN 1726-9679, Vienna, Austria

DOI: $10.2507 / 29$ th.daaam.proceedings.084

\begin{abstract}
The article presents an approach to organize control of energy installations which operate in conditions of uncertainty and badly predictable environment (e.g. wind turbines, water generators). The attractable feature of the proposal relates to possibility of balancing computational load of a low-level control node (namely, process automation controller - PAC) and a higher-level control node (namely, a computer running supervisory control and data acquisition system - SCADA in addition with knowledge base management system - KBMS). The architecture is described with the help of unified modelling language - UML, which appears to be a precondition for systematic use the model-based system engineering rules for the next steps of design and implementation of the control system.
\end{abstract}

Keywords: energy units; control in uncertainty; UML; KBMS; knowledge-based control system

\section{Introduction}

Modern ways of generating energy, such as wind farms, geothermal and solar energy, etc. are deployed and their importance is definitely big because of limitations of the Planet resources of coal, natural gas and petroleum, and harmful effects of waste produced by the civilization, as well as increasing request for power actually in all countries. Below control systems for wind farm and water generator are considered from a common viewpoint, and this corresponds to the concept of creating a digital twin for a complex process [1]. The main problem of wind energy is its variability. Power and rotor speed of a wind turbine are dependent on wind speed [2].

As it can be seen from the figure below, it's not enough just to let wind vane of wind turbine position the rotor head perpendicular to the wind, but it is also necessary to control the rotor speed to gain maximum mechanical power from the turbine on different wind speeds. Placing one turbine behind another will decrease the energy of wind flowing to the second turbine, after it flown through the first.

This aspect also should be taken into account in the control system design. Hardly-predictable wind nature leads us to use special control algorithms not only for wind turbine, but for wind farm in a whole. Methods for hardly formalizable tasks, for instance, neuro control and fuzzy logic should be used in this case. 


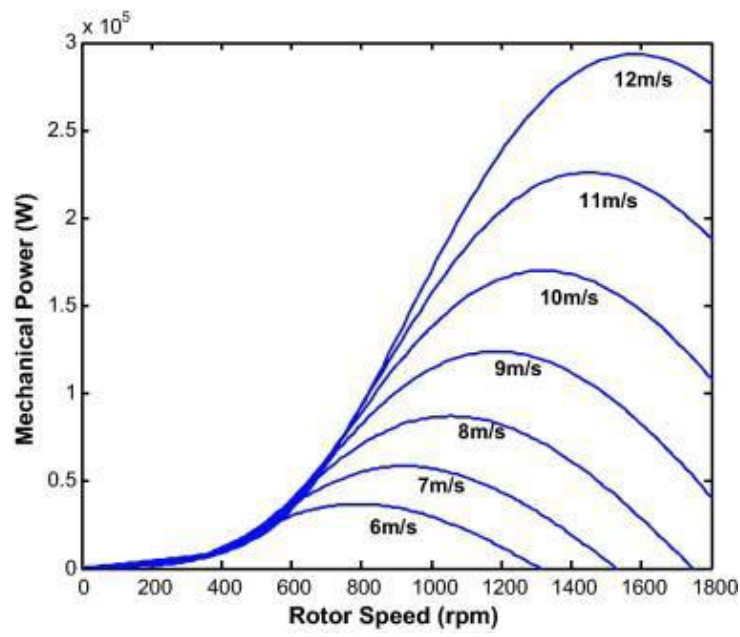

Fig. 1. Power and rotor speed relation on different wind speed

In [3] fuzzy logic techniques are used to build the algorithm for power maximization, produced by wind turbine. In [4] the neural network is used to maximize the power of wind turbine by managing its blades pitch and electrical inverter. As a result, the efficiency of using neural networks for this type of problem is stated, which exceeds the efficiency of PID controller usage. In [5] intellectual algorithm, based on neural network and fuzzy logic systems, allowing to produce energy-efficient work modes.

Similar problems relate to a hydro generator [6]. In this case power is a function of the hydraulic head and rate of fluid flow. The head is the energy per unit weight (or unit mass) of water. The static head can be calculated using proportion related to the difference in height through which the water falls. Dynamic head is defined by the velocity of moving water. Each unit of water can do an amount of work equal to its weight times the head. The power available from falling water can be defined from the flow rate and density of water, the height of fall, and the local acceleration due to gravity. Detailed calculation of the efficiency of a hydropower turbine will account for the head lost due to rise in tail water level due to flow, flow friction in the power canal or penstock, the location of the station and effect of varying gravity, the density of the water at ambient temperature, the temperature and barometric pressure of the air, and the altitudes above sea level of the forebay and tail-bay. For precise calculations, errors due to rounding and the number of significant digits of constants must be considered. In addition, effects of the season of the year should be considered as spring floods, influence of season winds on the water flow on open water surfaces prior to a water fall etc.

In both cases (wind and hydro turbines) complex structure, difficulties in detailed and exact description of its behaviour, changing conditions of work caused by the environment should be considered and, consequently, complex algorithms of control should be created, investigated and implemented which possibly require big computational power. In the same time good laws of control need a limited time of response (milliseconds or tens of milliseconds). In practice the latter means use of programmable logic controllers (PLCs) or process automation controllers (PACs). Although the last platforms of PACs which the leading vendors offer have much better performance and memory than ones 5 or 10 years ago, a number of algorithms need to use powerful regular desk-top computers as servers with very limited capabilities to solve real-time tasks with a response time mentioned above.

The modern techniques of using process automation controllers, supervisory control and data acquisition system and knowledge base management system with learning with a trainer and reinforcement learning technique are used. An approach to solve the problem of distribution the performance and memory among a soft-real-time server and a hard-realtime controller is proposed.

\section{Knowledge-based control system}

The proposed approach is based on the following considerations some of which are obvious nonetheless they are clearly mentioned below:

- The aim is to improve the control of the energy units using available statistics and current work of the system;

- Control of the energy process is implemented as interconnection of PAC and SCADA, functions of the latter are widened with the use of knowledge base management system;

- Available statistics is mapped into rules of KB by learning with a trainer, and processing of current work is converted into rules of KB by reinforcement learning;

- Quality of the control depends on a required response time of the PAC, and of performance of the PAC and PC running software applications;

- Processing of the rules closer to the energy unit by moving the execution from a computer to a controller as operative as possible is proposed. 
Learning with a trainer and reinforcement learning can be implemented using appropriate method, this paper does not describe and analyse them. Energy generators are the objects of control. We refer to wind generator and hydro generator as energy units to be considered from a common point of view. They have such parameters as nominal power, mode of work, coefficient of performance, etc. A number of operations can be fulfilled with them, such as switching on and off, going to a specific mode, etc. In addition, the energy units are dependent on environment as temperature, speed of wind or water flow.

From the other hand the low-level control system reads values of the mentioned above sensors and calculates commands which are directed to the object of control. In addition, the SCADA-system communicates with the controller: reads information about the state of the control from the PAC and sends high-level commands to it. This is the standard approach to build an ordinary control system which should meet the requirements of respond time, performance, reliability and availability. We will use Unified Modelling Language [7] and Modelio tool [8] to describe the system under consideration (Fig.2 with yellow elements).

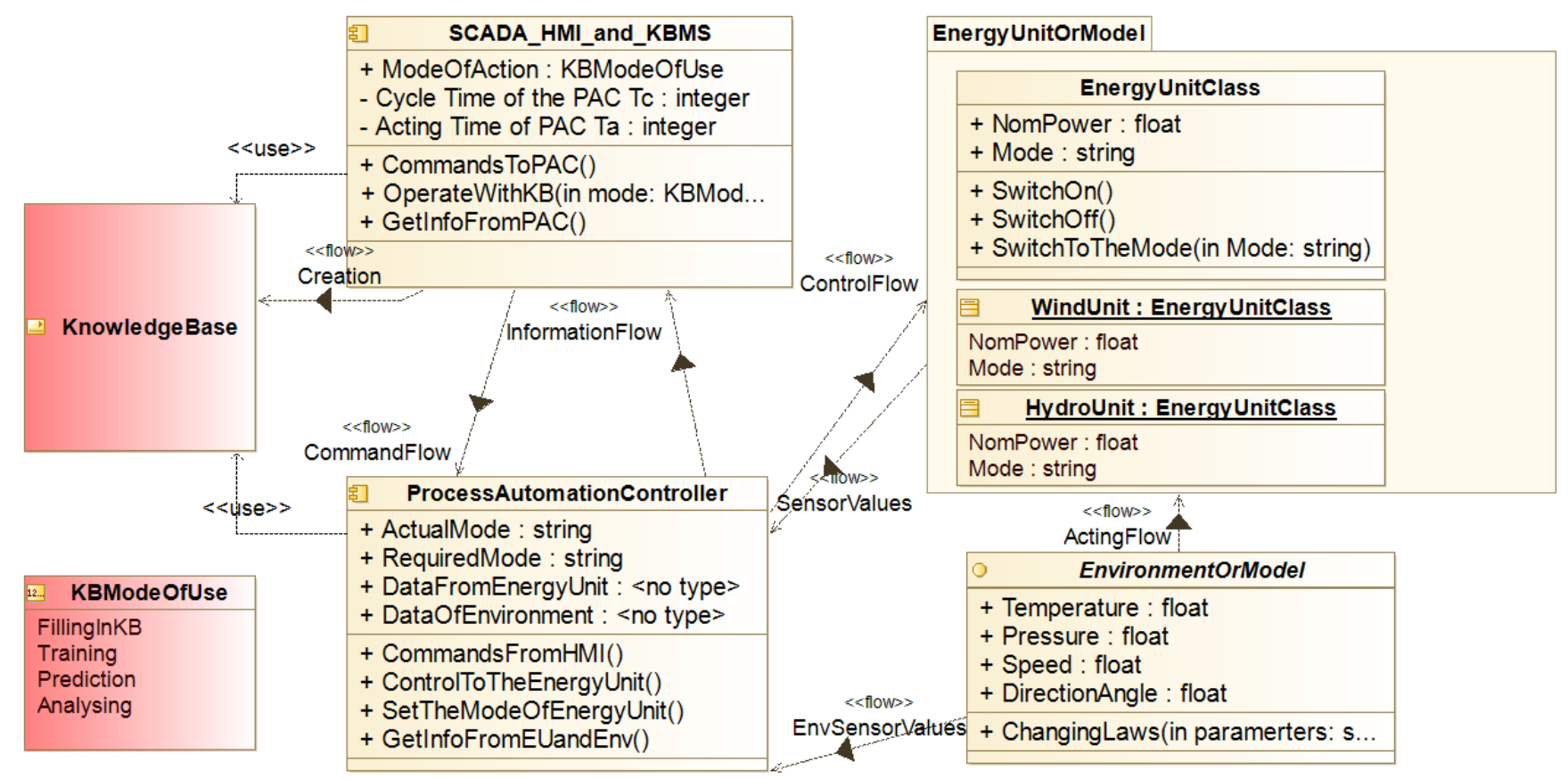

Fig. 2. Architecture of the Knowledge Based Control System

The architecture of the system is significantly changed if we add the new functionality as operations with the knowledge base (new elements are coloured with pink filling, Fig.2). We consider such modes of use of the system as filling the Knowledge Base with new rules, training of the system, use it for analysing, use it for prediction.

\section{A way of possible implementation}

Consider the next step for a possible implementation of the proposed control.

Let $\mathrm{Tc}$ is a required response time (cycle time) of the control system. It depends on properties of the energy unit.

Let $\mathrm{Ta}$ is an actual time of a computational load (scan time) of the controller for a given cycle of the PAC. For normal operation of the control system it is necessary that $\mathrm{Ta}<\mathrm{Tc}$.

The low-level node of the control system, PAC, starts with the initial configuration and initial set of operating rules. The higher-level node of the control system starts with learning with a trainer using available statistics. The latter can take a long period of time and is done with no communication with the controller. As soon as the training is finished the rules which the controller uses can be updated. Then the mode of operation of the SCADA+KBMS can be chosen: analyze the work or predict parameters of the energy unit in coming period.

If the analyzing mode is chosen, then it is necessary to compare the scan time and the cycle time of the PAC. If the former is considerably less than the latter, then the higher-level node can download the updated set of rules in the PAC. If the scan time and the cycle time are equal or have close values, then we have to keep the current set of rules and continue to work with parameters which have been achieved up to the moment of the analysis. If the scan time is more than the cycle time of the PAC, then it is necessary to provide better performance and go back to some previous set of rules in order to make acting scan time less than required cycle time of the PAC. 
If the prediction mode is chosen, then the PAC works with current set of rules, but the server starts to form the cone of the future parameters for the moment of the request. Then the results of the prediction can be evaluated and the rules of KB can be updated. The described approach is presented on the Fig. 3 as a possible way of implementation.

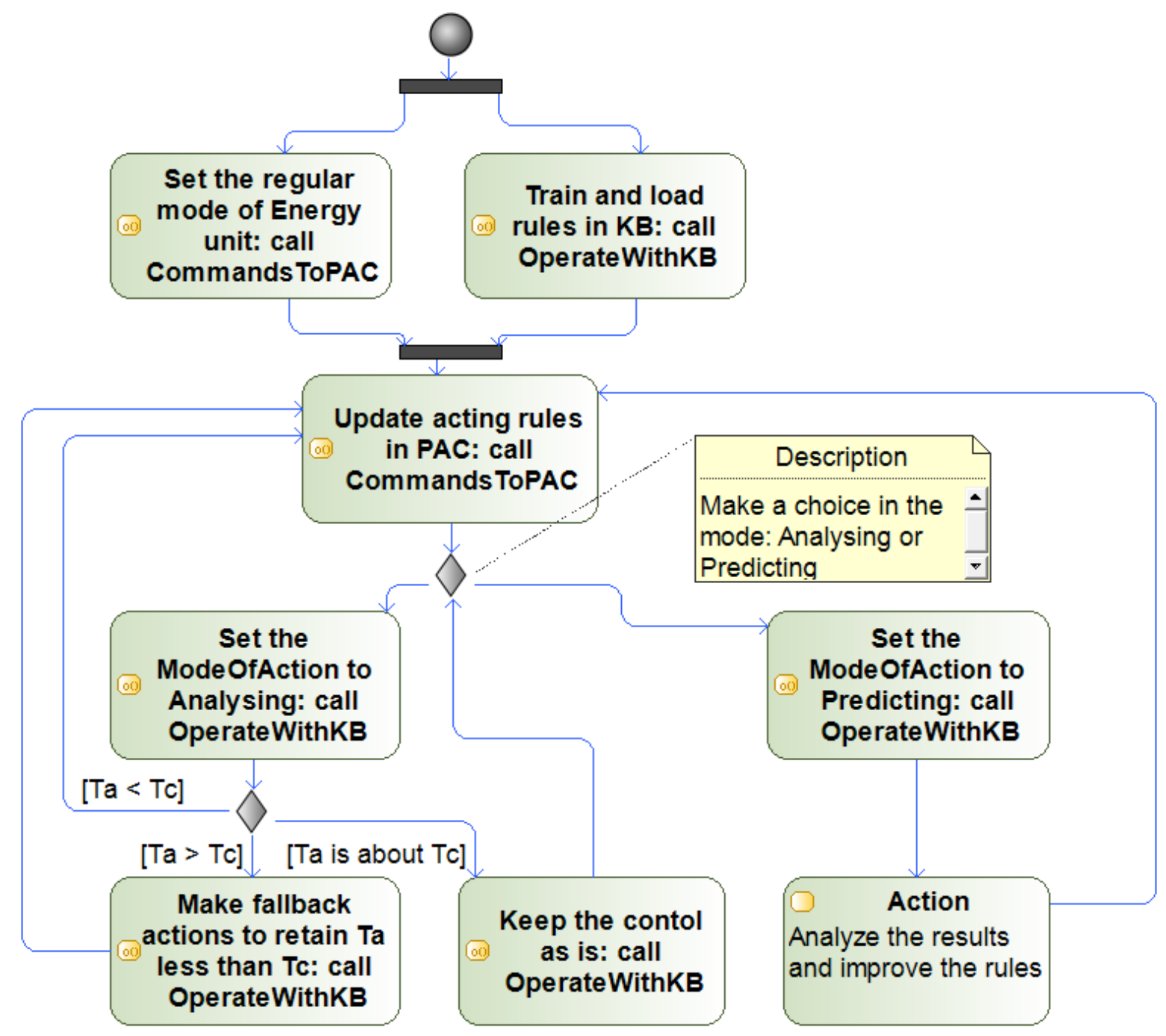

Fig. 3. A way to organize the Knowledge-Based Control System

The inscriptions in the rectangular graphical elements (Fig.3) mainly present the operations of classes and components listed in graphical elements (Fig.2).

\section{Conclusion}

The problem of design of the control system for an energy unit operating in uncertainty caused by changing environment (for instance, wind turbine and hydro generator) has been considered. The approach to reach better performance has been described based on the use of knowledge base management system in addition to a regular control system containing a process automation controller and a supervisory control and data acquisition system. The architecture and the way to organize the operation of knowledge-based control system have been proposed. The possibility to balance the computational load in two-component system of the controller and the server running KBMS+SCADA can be provided. This will give better quality of the control and finally result to more value of coefficient of performance of the energy unit.

A limitation of the approach relates to the fact that it is actually impossible to analytically calculate the effect in increasing the productivity of the energy unit because the set of rules placed in the controller (and its consequences) is changing dynamically and can not be foreseen for analytical evaluation.

The next steps of the work can implement and investigate the methods of creating and updating rules of KB in relation to their influence on the controller scan time. In addition, advanced methods of control can be considered in which the required cycle time (response time of the control system) can be changed according to some external conditions. 


\section{Acknowledgments}

The article is published with support of the project Erasmus+ 573545-EPP-1-2016-1-DE-EPPKA2-CBHE-JP Applied curricula in space exploration and intelligent robotic systems (APPLE) and describes the part of the project conducted by Peter the Great Saint Petersburg Polytechnic University.

\section{References}

[1] Ponomarev, K.; Kudryashov, N. \& Popelnukha, N. (2017) Main Principals and Issues of Digital Twin Development for Complex Technological Processes, Proceedings of the 28th DAAAM International Symposium, pp.0523-0528, B. Katalinic (Ed.), Published by DAAAM International, ISBN 978- 3-902734-11-2, ISSN 1726-9679, Vienna, Austria

[2] Khritonenkov, A.; Taranetc, I.; Shkodyrev \& V.; Potekhin, V. (2013) Intellectual control algorithm for autonomous wind farm, Proceedings of International Conference on Distributed Intelligent Systems and Technologies (DIST), 2013 July 1-4, St.-Petersburg, Russia, pp.39-46

[3] Azouz, M.; Shaltout, A. \& Elshafei M. A. L. (2010) Fuzzy Logic Control of Wind Energy Systems, Proceedings of the 14th International Middle East Power Systems Conference (MEPCON'10), 2010 December 19-21, Cairo Univ., Egypt

[4] Kyoungsoo, Ro \& Han-ho Choi (2005) Application of neural network controller for maximum power extraction of a grid-connected wind turbine system, Electrical Engineering

[5] Surkov M. (2011) Increasing energetic efficiency of autonomous wind-diesel electrotechnical complexes, Tomsk Tech.Univ. (Сурков М., Повышение энергетической эффективности автономных ветродизельных электротехнических комплексов, Томский гос.техн.ун-т, 2011)

[6] Schavelev, D., (1981) Hydro-energy installations (hydro power plants, pump stations and hydro-accumulating power plants), Leningrad (Щавелев, Д., Гидроэнергетические установки (гидроэлектростанции, насосные станции и гидроаккумулирующие электростанции, Л., 1981)

[7] http://www.uml.org (2018) Object Management Group, accessed on 2018-06-01

[8] http://www.modelio.org (2018) Modelio, the open source modeling environment, accessed on 2018-06-01 